
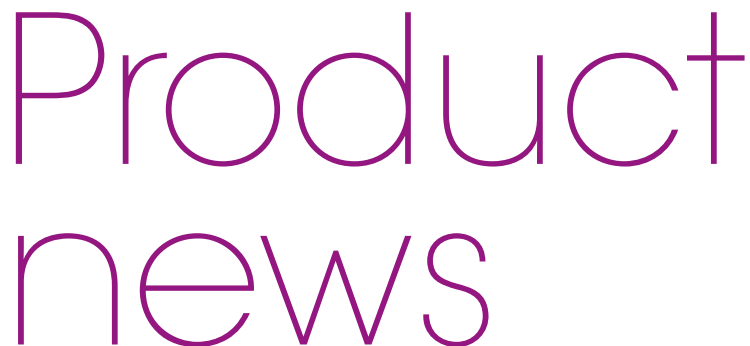

Product news is provided as a service to readers using text and images from the manufacturer, supplier or distributor and does not imply endorsement by BDJ Team. Normal and prudent research should be exercised before purchase or use of any product mentioned.

\section{SAY CHEERIO TO PERIO}

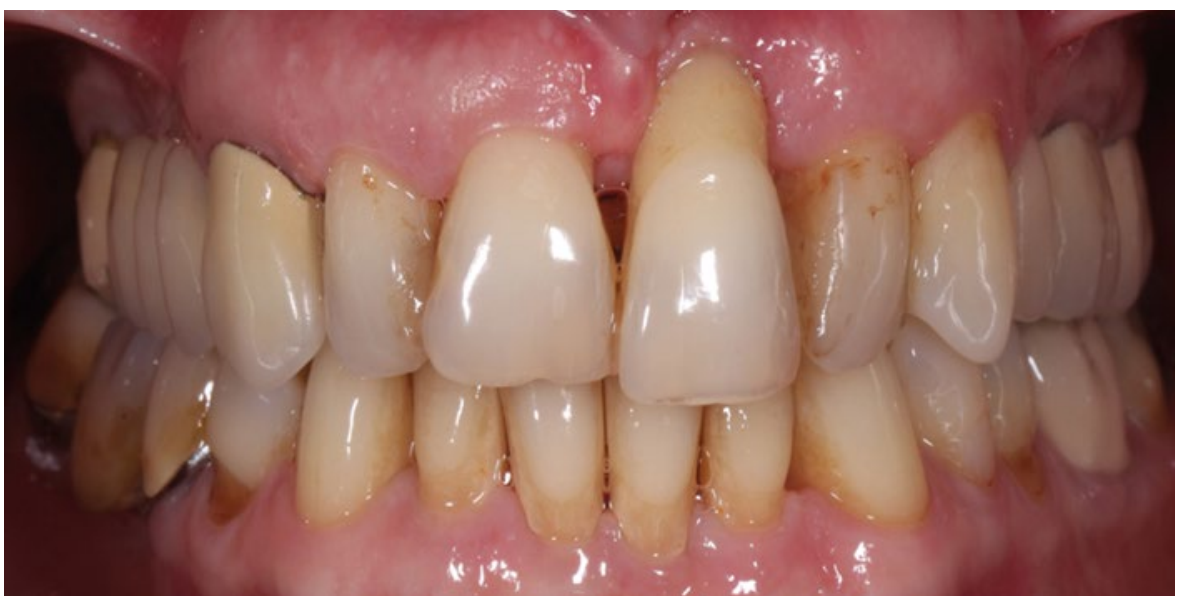

Assessing the true extent of periodontitis can be difficult. PROPACS from PRO Diagnostics UK is a secure cloud-based storage system which can be used to assess and monitor periodontitis. You simply send radiographs to their team of specialist radiologists and they will create a PerioGuide report.

This report uses an easy to understand colour coded system to assess the severity of periodontitis and also give information such as the amount of bone loss at each tooth site - everything you need to accurately classify the severity of your patient's periodontitis and treat it accordingly.

For more information, please visit www. prodiagnostics.co.uk or email sales@ prodiagnostics.co.uk.

\title{
REDUCE RISK OF PATIENT DATA LOSS
}

One of the worst things that could happen to your dental practice is a fire in which you lost all your patient data. Ensure your

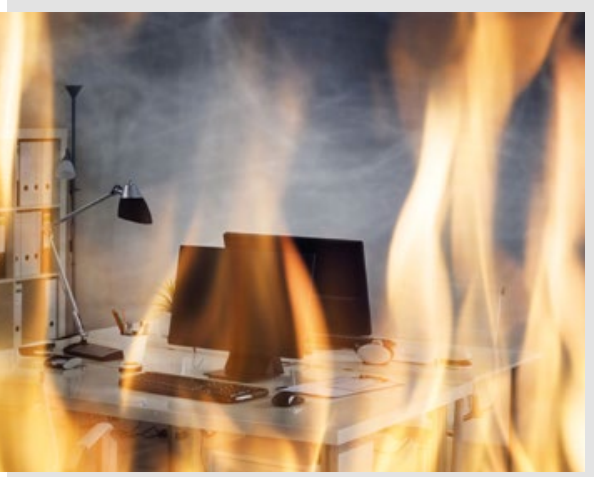

practice keeps sensitive patient images safe by choosing PROPACS from PRO Diagnostics UK.

A cloud based, highly encrypted storage solution for images, PROPACS not only stores images safely but can also protect said images from cyber threats such as viruses, malware and hackers. This means that even when the unspeakable happens your patient images will be ready when you need them.

Don't let a disaster destroy your data, choose PROPACS.

More information is available by visiting www.prodiagnostics.co.uk or emailing sales@prodiagnostics.co.uk.

\section{COLLABORATION PROMISES ONLINE REPUTATION SOLUTION}

Working Feedback, the review specialists, have joined forces with Systems For Dentists (SFD), the software provider for dental practice management. Since 1987 , dental practices have looked to Systems For Dentists as the independent source for planning, running and management of their dental business. The online reputation management tool called Kudos is provided in partnership with Working Feedback and the integration makes patient feedback a seamless, automated process for practices using Systems For Dentists practice management software.

The new tool helps dental businesses to gain a clearer understanding of the patient journey which they can use to improve upon what they do, increase additional treatment uptake, turbocharge their online reputation and deliver exceptional customer service that sets the practice apart from its competitors.

The Kudos tool also attracts new patients by sharing review ratings with Google, NHS and key social media platforms such as Facebook.

Working Feedback is a leading solution for patient reviews and enjoys strategic partnerships with Practice Plan, NHS Choices and the Care Quality Commission; it works with hundreds of independent dental practices in helping them grow their business through patient feedback.

More information about the Systems For Dentists tool Kudos is available by visiting https://www.sfd.co/kudos.html and more about Working Feedback's ability to transform a patient journey into business growth can be seen at https:// www.workingfeedback.co.uk/dentist/ cherrytree-dentalcare. 